\title{
Astronomi Başarı Testi Geliştirme: Geçerlik ve Güvenirlik Çalışması*
}

\author{
Developing an Astronomy Achievement Test: Validity and Reliability Study
}

Nagehan DEMİR ${ }^{\dagger} \&$ Fulya ÖNER ARMAĞAN ${ }^{\ddagger}$

Geliş Tarihi: 26.02.2019 $\quad$ Kabul Tarihi: 30.06.2019 $\quad \frac{\text { *. }}{*} \quad$ Yayın Tarihi: 01.07.2019

Özet

Bu çalışmanın amacı, 7. sınıf "Güneş Sistemi ve Ötesi: Uzay Bilmecesi" ünitesinde fen bilimleri öğretim programı kazanımları doğrultusunda bir başarı testi geliştirmektir. Bu amaçla öncelikle ünite kazanımlarına uygun olarak ve alan yazından da yararlanılarak 31 soru hazırlanmıştır. Testin kapsam geçerliği için belirtke tablosu oluşturulmuş ve uzman görüşleri alınmıştır. Hazırlanan 31 soruluk astronomi başarı testi 2017-2018 eğitim öğretim yılında 150 7. sınıf öğrencisine pilot çalışma olarak uygulanmıştır. Test sorularına madde analizi yapılarak madde ayırt edicilik ve güçlük indeksleri hesaplanmıştır. Yapılan analizler sonucunda bazı sorular düzeltilerek ve bazı sorular ise çıkartılarak testteki soru sayısı 27'ye düşürülmüştür. Pilot uygulamadan sonra geçerlik ve güvenirlik çalışmaları sonucunda 27 çoktan seçmeli sorudan oluşan başarı testi 150 yedinci sınıf öğrencisine tekrar uygulanmıştır. Uygulanan astronomi başarı testinin ortalama madde ayırt edicilik indeksi .38 ve ortalama madde güçlük indeksi .60 olarak tespit edilmiştir. Nihai Testin Cronbach alfa güvenirlik katsayısı .752 olarak hesaplanmıştır. Sonuçlar, 7. sınıf astronomi konusunda geçerli ve güvenilir, dört seçenekli çoktan seçmeli 27 soruluk bir test geliştirildiğini göstermiştir. Geliştirilen bu test fen eğitimi alanındaki araştırmacılar tarafından kullanılabilir.

Anahtar kelimeler: Astronomi başarı testi, geçerlik, güvenirlik, test geliştirme

\section{Abstract}

The aim of this study is to develop a success test for the science program curriculum gains in 7 th grade "Solar System and Beyond: Space Puzzle" unit. For this purpose, 31 questions were prepared in accordance with the unit gains and by using the literature. For the validity of the scope of the test, a table of specifications was created and expert opinions were obtained. The 31-question astronomy achievement test was applied as a pilot study to 150 7th grade students in 2017-2018 academic year. Item discrimination and difficulty indexes were calculated by item analysis. As a result of the analyzes,

\footnotetext{
* Bu çalışma, birinci yazarın Erciyes Üniversitesi Bilimsel Araştırma Projeleri Birimi tarafından SDK-2018-8367 kodlu proje ile desteklenen “Astronomi Konularının Öğretiminde 5E Öğrenme Modelinin 7. Sınıf Öğrencilerinin Akademik Başarılarına ve Tutumlarına Etkisi” başlıklı doktora tez çalışmasının bir bölümünü içermektedir.

${ }^{+}$Doç. Dr. Erciyes Üniversitesi, Eğitim Fakültesi, Matematik ve Fen Bilimleri Eğitimi Bölümü, fulyaner@yahoo.com

‡ Doktora öğrencisi, Erciyes Üniversitesi, Fen Bilgisi Eğitimi, nagehandemir66@gmail.com
} 
some questions were corrected and some questions were removed and the number of questions in the test was reduced to 27. After the pilot application, the success test consisting of 27 multiple choice questions was re-applied to 150 seventh grade students as a result of validity and reliability studies. The average item discrimination index of the astronomy achievement test was .38 and the average item difficulty index was .60. Cronbach alpha reliability coefficient of the final test was calculated as .752.The results showed that a valid and reliable test for the 7 th grade astronomy was developed with a 27-question fourchoice multiple choice test. This test can be used by researchers in the field of science education.

Key words: Astronomy achievement test, validity, reliability, test development

\section{Giriş}

Ölçme, belirli kurallar ve yöntemlere göre bireylerin belirli özelliklerini sayısal olarak ifade etmek için gerekli araçların seçilmesi süreci olarak tanımlanmaktadır. Ölçme, öğretim sürecinin en öncelikli parçası olarak karşımıza çıkmaktadır. Öğretim süreci ne kadar modern ve üst düzey olursa olsun, eğer öğretim sürecini ölçmede kullanılan araçlar yetersiz ise bu durum öğretimin değerlendirilmesini de olumsuz etkileyecektir. Ölçme işleminde her bir öğrencinin belirli bir özelliğge veya niteliğe sahip olup olmadığı veya ne derece sahip olduğu belirlenmeye çalışılır (Atılgan, 2013). Değerlendirme ise ölçme sonuçlarının bir ölçütle karşılaştırılarak ölçülen nitelik hakkında karar verilmesidir (Yılmaz, 2004). Öğrencilerin başarılarını belirlemek için öncelikle tüm öğrenci kazanımlarını kapsayan iyi hazırlanmış ölçme araçlarına gereksinim vardır. Günümüzde öğrenci kazanımlarının değerlendirilmesinde kullanılan geleneksel ölçme araçları; çoktan seçmeli sorular, doğru yanlış soruları, kısa cevaplı sorular, boşluk doldurma soruları ve eşleştirme sorularıdır (Karip, 2012). Bu değerlendirme türlerinden çoktan seçmeli sorular eğitmenlerin en çok kullandıkları ölçme araçlarıdır.

Alan yazında çoktan seçmeli ölçme araçları geliştirmeye yönelik pek çok çalışmaya rastlanmaktadır (Demir, Kızılay ve Bektaş, 2016; Kızkapan ve Bektaş, 2018; İpek Akbulut ve Çepni, 2011; Saylan Kırmızı̈ül ve Kaya, 2019). Fen eğitimi alanlarından biri olan astronomi alanına son dönemlerde oldukça önem verilmektedir. 2018 yılı Fen Bilimleri Dersi Öğretim Programı́nın temel amaçlarından biri de "astronomi, biyoloji, fizik, kimya, yer ve çevre bilimleri ile fen ve mühendislik uygulamaları hakkında temel bilgiler kazandırmaktır." (MEB, 2018). Bu temel amaç çerçevesinde 2018 yılı Fen Bilimleri Dersi Öğretim Programı ile beraber astronomi üniteleri "Dünya ve Evren" konu alanı içinde 3. sınıftan itibaren başlamaktadır. Güncellenen öğretim programı ile beraber "Dünya ve Evren" konu alanı kapsamındaki astronomi üniteleri her eğitim seviyesinin ilk ünitesi olarak yer almaktadır. Farklı astronomi konularında, birbirinden farklı amaçlara yönelik ve çalışma grupları ile yürütülen araştırmalar bulunmaktadır.

Alan yazındaki astronomi alanıyla ilgili çalışmalar incelendiğinde; çalışmaların genellikle öğrencilerin kavram yanılgılarını belirlemeye yönelik olduğu tespit 
edilmiştir (Alın ve İzgi, 2017; Baloğlu-Uğurlu, 2005; Bostan, 2008; Bülbül, İyibil ve Şahin 2011; Kurnaz ve Değirmenci, 2011; Starakis ve Halkia, 2010). Astronomi eğitiminde çeşitli öğretim yöntemleri kullanılarak temel astronomi kavramların daha iyi öğrenilerek öğrenci başarısının arttırıldığı araştırmalar yapılmıştır (Gündoğdu, 2014; Kallery, 2011; Trumper, 2006). Bunun yanında astronomiye yönelik tutum ile ilgili çalı̧̧malar da yapılmıştır (Arıkurt vd., 2015; Balbağ ve Erdem, 2017; Bektaşlı, 2013,2016; Demir ve Öner Armağan, 2019; Kallery, 2011; Türk ve Kalkan, 2017a, 2017b). $\mathrm{Bu}$ çalışmalar incelendiğinde astronomi konularına yönelik veri toplama aracı geliştirme çalışmalarının olduğu da tespit edilmiştir. (Bailey, 2012; Demirçall, 2016; Gülen ve Demirkuş, 2014; Gündoğdu, 2014; Balcı, 2018; Buluş Kırıkkaya ve Şentürk 2018; Slater, 2015; Şenel Çoruhlu, 2013; Wallace, 2011; Trumper, 2006; Türk, 2015). Bu çalışmalardaki astronomi kavramları incelendiğinde, Dünya (Baloğlu Uğurlu, 2005; İbret ve Aydınözü, 2011; İyibil, 2010; Kikas, 2005), Ay ve evreleri (Bekiroğlu, 2007; Trundle, Atwood \& Christopher, 2002, 2006, 2007; Öztürk \& Uçar, 2012), yıldızlar ve özellikleri (Agan, 2004; Bailey, 2006; İyibil, 2010; İyibil \& Sağlam Arslan, 2010; Kurnaz, 2012), Güneş (İyibil, 2010; Kikas, 2005), gezegen (Ekiz \& Akbaş, 2005; İyibil, 2010), uydu (İyibil, 2010), kuyruklu yıldız ve takımyıldızı (Kurnaz, 2012), evren (Baloğlu Uğurlu, 2005), uzay (Şahin, 2001) gibi temel astronomi konu ve kavramlarına rastlanırken; bu çalı̧̧malarda Dünya, Ay, Ay'ın evreleri ve yıldızların özellikleri konularında daha fazla olduğu görülmektedir. Alan yazındaki bu çalışmalar arasından sadece "Güneş Sistemi ve Ötesi: Uzay Bilmecesi" ünitesi kazanımlarına yönelik geliştirilen başarı testlerinin de sınırlı sayıda olduğu görülmektedir (Arıkurt, 2014; Buluş-Kırıkkaya ve Şentürk, 2018; Çepni ve Şenel Çoruhlu, 2014; Demirçalı, 2016; Deniş Çeliker, 2012; Gülen ve Demirkuş; 2014; Gündoğdu, 2014; Türk, 2015). Bu bakımdan bu çalışmada 7. sınıf "Güneş sistemi ve ötesi: Uzay Bilmecesi" ünitesi için geçerli ve güvenilir bir ölçüm aracı geliştirmek amaçlanmıştır.

\section{Yöntem}

\section{Araştırmanın deseni}

$\mathrm{Bu}$ çalışma nicel araştırma yöntemlerinden tarama deseni kullanılarak yapılmıştır. Bir grubun belirli özelliklerinin belirlenmesi için verilerin toplanmasını amaçlayan çalışmalara tarama araştırması denir (Fraenkel, Wallen, \& Hyun, 2012). Örneklemden toplanan veriler sayesinde, evrenin düşünceleri veya inanışları hakkında nicel ve sayısal betimlemeler yapılmasını sağlar (Fraenkel, Wallen, \& Hyun, 2012).

\section{Örneklem}

Bu çalışma 2017-2018 Eğitim öğretim yılında, Kayseri İli Melikgazi ilçesinde 7. sinıfta öğrenim gören 300 öğrenci ile yürütülmüştür. 


\section{Veri toplama araci}

\section{Astronomi başarn testi}

Öğrencilerin astronomi konularındaki başarılarını ölçmek için Astronomi Başarı Testi (ABT) geliştirilmiştir. Başarı testinin hazırlanması için öncelikle ortaokul programına göre 7. Sınıf "Güneş Sistemi ve Ötesi: Uzay Bilmecesi” ünitesinin kazanımları dikkate alınarak alan-yazın taraması yapılmıştır.

ABT geliştirme sürecinde yapılan işlemlere aşağıda maddeler halinde yer verilmiştir.

- ABT geliştirilmeden önce 7. Sınıf “Güneş Sistemi ve Ötesi: Uzay Bilmecesi” ünitesinin kazanımları dikkate alınarak alan-yazın taraması yapılmıştır ve temel astronomi kavramları belirlenmiştir.

- Ünitenin her bir kazanımı için bir soru yazılması planlanmıştır. "Güneş Sistemi ve Ötesi: Uzay Bilmecesi" ünite kapsamında 'gök cisimleri', 'güneş sistemi' ve 'uzay teknolojisi' konularının yer aldığ 19 kazanım bulunmaktadır. Uzayda bulunan gök cisimleri konusuna ait sekiz alt kazanıma ilişkin 10 soru, Güneş sistemi konusuna ait sekiz alt kazanıma ilişkin 10 soru, uzay araştırmaları konusuna ait 11 alt kazanıma ilişkin 11 soru hazırlanmıştır. Başarı testi soruları her bir kazanımın içerdiği alt kazanımlarda dikkate alınarak 31 soru olarak hazırlanmıştır.

- Taslak ABT'nin ilk hali 31 soru olarak hazırlanmıştır. Testin kapsam geçerliliğini sağlamak için hazırlanan taslak ABT’nin kapsadığı kazanımlar ile ilgili belirtke tablosu hazırlanmıştır. Kazanımların listesi ve belirtke tablosu Tablo 2.'de verilmiştir.

- Soru havuzu oluşturulduktan sonra maddeler alanında uzman iki fen eğitimci ve on yıllık deneyime sahip iki öğretmenin görüşüne sunularak uzman görüşü alınmıştır. Tüm uzmanlara testin ana amacı hakkında bilgi verilmiş ve değerlendirme yapmaları istenmiştir. Uzmanların görüşleri dikkate alınarak alan yazından alınan bazı sorular öğrenim seviyesine ve kazanımlara uygun şekilde revize edilmiş veya değiştirilerek testte gerekli düzeltmeler yapılmıştır. 1.,5.,10. ve 20. sorular araştırmacı tarafından geliştirilmiştir.

- Test öğrencilere uygulanarak cevaplama süreleri, anlamakta zorluk çektikleri ifade olup olmadığı test edilmiştir. Öğrencilerin yaklaşık olarak 40 dakikada testi cevaplayabildikleri gözlenmiştir. Ayrıca test sorularının anlaşılabilirliği konusunda öğrencilerden olumsuz geri dönüt olmamıştır.

- Testin pilot uygulamaları yapılmıştır. Ardından madde analizlerine geçilmiştir. ABT'den elde edilen sonuçların puanlanmasında; doğru cevaplar 1 puan, yanlış cevaplar, boş bırakanlar veya aynı madde için birden fazla cevabı işaretlemiş olanlar 0 puan olarak değerlendirilerek her öğrencinin 
testten aldığ1 toplam puan hesaplanmıştır. Pilot çalışmanın madde analizleri sonucunda 4 maddenin testten çıarılmasına karar verilmiştir.

- Her bir kavramın en az bir soru ile ölçülmesi ve ünite kazanımlarının testte yer alması ve geçerlik-güvenirlik çalışmaları göz önünde bulundurularak, toplam soru sayısı 27 olarak belirlenmiştir.

Yukarıda verilen basamaklar takip edilerek hazırlanan testin sorularının alındığ kaynaklar

Tablo1.Test Sorularının Alındı ğı Kaynaklar

\begin{tabular}{|c|c|c|}
\hline Soru Numarası & Alıntı Yapılan Kaynak & Benzer Soru Numarası \\
\hline \multicolumn{3}{|l|}{1} \\
\hline 2 & Gündoğdu,2014 & 8.soru \\
\hline 3 & Deniş Çeliker,2012 & 28.soru \\
\hline 4 & PYBS,2014 & 11.soru \\
\hline \multicolumn{3}{|l|}{5} \\
\hline \multirow[t]{2}{*}{6} & Çoruhlu,2013 & 12.soru \\
\hline & Arıc1,2013 & 3.soru \\
\hline \multirow[t]{2}{*}{7} & Türk,2015 & 19.soru \\
\hline & Demirçalı,2016 & 18.soru \\
\hline 8 & Gündoğdu,2014 & 7.soru \\
\hline 9 & Salter,2015 & 9.soru \\
\hline \multicolumn{3}{|l|}{10} \\
\hline \multirow[t]{4}{*}{11} & Taşcan,2013 & 19.soru \\
\hline & P1sa,2015 & 1.soru \\
\hline & Slater,2015 & 11.soru \\
\hline & Agan,2004 & 3.soru \\
\hline 12 & Çoruhlu,2013 & 3.soru \\
\hline \multirow[t]{2}{*}{13} & PYBS,2012 & 13.soru \\
\hline & Türk,2015 & 16.soru \\
\hline 14 & Çoruhlu,2013 & 4.soru \\
\hline \multirow[t]{2}{*}{15} & PYBS,2013 & 9. soru \\
\hline & PYBS,2017 & 10.soru \\
\hline \multirow[t]{2}{*}{16} & PYBS,2009 & 7. soru \\
\hline & PYBS,2015 & 11.soru \\
\hline \multirow[t]{2}{*}{17} & Çoruhlu,2013 & 6.soru \\
\hline & Wallace,2011 & 1.soru (Part I) \\
\hline
\end{tabular}




\begin{tabular}{lll}
\hline 18 & Trumper,2001 & 13.soru \\
\hline 19 & Deniş Çeliker,2012 & 24 ve 32.soru \\
\hline 20 & & \\
\hline 21 & PISA,2015 & 21. soru \\
& Colombo,Jr.Silva \& Aroca,2010 & 3.soru \\
\hline 22 & Gündoğdu,2014 & 5.soru \\
& Çoruhlu,2013 & 7. soru \\
& Taşcan,2013 & 17. soru \\
\hline 23 & Trumper,2006 & 17. soru \\
& Bailey,2012 & 7. soru \\
\hline 24 & PYBS,2012 & 12. soru \\
\hline 26 & Demirçal,,2016 & 19. soru \\
\hline 27 & Çoruhlu,2013 & 11. soru \\
\hline
\end{tabular}

\section{Pilot uygulama}

Konuların alt kazanımlarına göre madde dağılımı verilen taslak ABT hazırlandıktan sonra pilot uygulamaları yapılmıştır. Testin ön pilot çalışmasında öğrenciler test sorularını 40'dakikada cevaplandırmışlardır. Yapılan uygulama sonrasında elde edilen verilerin SPSS 22. paket programında betimsel istatistik analizi ve normal dağılıma uygunluğunu test etmek amaciyla normallik testleri (Kolmogorov-Smirnov ve Shapiro-Wilk) hesaplanmıştır. Betimsel istatistik sonucunda aritmetik ortalama (148), ortanca (152) ve mod (174) değerlerinin birbirine yakın olduğu görülmektedir. Ayrıca, basıklık (-.372) ve çarpıklık (-.901) değerlerinin +1 ile 1 değerleri arasında olduğu görülmektedir. Dolayısıyla basıklık ve çarpıklık değerlerinin istenilen aralıkta olması ve aritmetik ortalama, ortanca ve mod değerlerinin birbirine yakın olması sebebiyle astronomi başarı testi puanlarının normal dağıldığı kabul edilmiştir (Clements, 1999; Karaatlı, 2006). KolmogorovSmirnov ve Shapiro-Wilk testi sonuçlarından öğrencilerin başarı testi puanlarının normal dağılımdan anlamlı bir farklılık göstermediği görülmüştür (.20>.05). Pilot uygulamadan sonra geçerlik ve güvenirlik çalışmaları sonucunda test 27 madde olarak belirlenmiştir. Pilot çalışma kapsamında yapılan madde analizi çalışmaları bulgular kısmında ayrıntılı olarak verilmiştir.

\section{Verilerin analizi}

Çalışmada ABT için geçerlik ve güvenirlik analizleri yapılmıştır. Çoktan seçmeli başarı testinden elde edilen nicel veriler MS Excel 2013 ve SPSS 22 programları ile analiz edilmiştir. Testin geçerlik ve güvenirlik çalışmaları kapsamında betimsel 
istatistikler, madde analizi ve açımlayıcı faktör analizi (AFA) teknikleri kullanılmıştır. Testi doğru cevaplayan öğrencilerin cevapları SPSS 22 programına "1", yanlış ve boş cevaplar ise " 0 " olarak girilmiştir. Testten alınabilecek en yüksek puan 27, en düşük puan ise sıfır olarak belirlenmiştir. Kapsam geçerliği için uzman görüşü alınmıştır. Uzman görüşleri doğrultusunda düzeltilen testin yap1 geçerliğini sağlamak için madde analizi yapılmalıdır (Turgut, 1992). Testin madde analizi için, öğrencilerin puanları yüksekten düşüğe doğru sıralanmıştır. Puan sıralamasına göre öğrencilerden \% 27'lik alt ve \% 27'lik üst grup olmak üzere iki grup belirlenmiştir. Alt ve üst gruplara göre soruların madde ayırt edicilik ve güçlük indeksleri hesaplanmıştır. Testin güvenirlik çalışması için yukarıda da bahsedildiği gibi SPSS 22 programı kullanılarak Cronbach alfa güvenirlik katsayısı hesaplanmıştır.

\section{Bulgular}

Çalışmanın bu kısmında, geliştirilen astronomi başarı testinin geçerlik ve güvenirlik çalışmaları verilmiştir.

\section{Testin geçerlik çalışması}

\section{Kapsam geçerliği}

Kapsam geçerliği başarı testlerini geliştirmede başlangıç noktasını oluşturur. Testler için belirtke tablosu hazırlamak testin kapsam geçerliğini arttırmada kullanılan bir yoldur (Büyüköztürk vd., 2012). Ölçme aracında yer alan her bir soru, ilgili olduğu kazanımı yoklamak koşuluyla ölçme kapsamında yer alan tüm kazanımları temsil edebilecek nitelikteyse kapsam geçerliği sağlanmış olur (Yurdabakan, 2008). Bu amaçla çalışmada uygulanacak testin kapsam geçerliğini sağlamak için ilk olarak, ünite kazanımlar ile ilgili belirtke tablosu hazırlanmıştır Belirtke tablosu Haladyna (1997) Taksonomisi'nin anlama, problem çözme ve eleştirel düşünme süreçlerine göre hazırlanmıştır. Yaratıcılık düşünme süreci kullanılmamıştır. Her kazanımdan bir soru hazırlanmasına dikkat edilmiştir. ABT'ndeki sorularda ölçülen davranış ve kazanımlarda ölçülmek istenen davranışın uyumu bakımından sorular alan uzmanlarına incelettirilerek, uzmanların dönütleri doğrultusunda sorularda düzeltilmeler yapılmıştır.

Başarı testi için her bir kazanıma yönelik en az bir tane soru içeren 31maddelik bir soru havuzu hazırlanmıştır. Soru havuzunda yer alan sorular; daha önce astronomi konularında araştırma yapan (Arıcı, 2013; Demirçalı, 2016; Baltacı, 2013; Bailey, 2012; Gündoğdu, 2014; Öz, 2004; Slater, 2015; Taşcan, 2013; Trumper, 2001; Trumper, 2006; Türk, 2015; Wallace, 2011; Yılmaz 2014) araştırmacılar tarafından geçerliği ve güvenirliği sağlanarak geliştirilen başarı testlerinden, uluslararası öğrenci başarılarını değerlendirme programı (PISA) sorularından, MEB'in 2000-2017 yılları arasında yapmış olduğu PYBS (Parasız Yatılılık ve Bursluluk Sınavı) gibi merkezi sınavlarda 
yer alan sorulardan, MEB tarafından onaylanmış fen bilimleri ders kitaplarından yararlanılarak araştırmacı tarafından hazırlanmıştır.

$\mathrm{Bu}$ doğrultuda hazırlanan testin kazanımları ve testte karşılık geldiği maddeler Tablo 2.'de verilmiştir.

Tablo 2. Haladyna (1997) Taksonomisi Kazanım Belirtke Tablosu

\begin{tabular}{|c|c|c|c|c|}
\hline \multirow[t]{2}{*}{$\begin{array}{l}\text { Soru } \\
\text { No }\end{array}$} & \multirow{2}{*}{ Soruların İçerdiği Kazanımlar } & $\begin{array}{l}\text { Bilişsel } \\
\text { Süreçleri) }\end{array}$ & Özellikler & (Düşünme \\
\hline & & Anlama & $\begin{array}{l}\text { Problem } \\
\text { Çözme }\end{array}$ & $\begin{array}{l}\text { Eleştirel } \\
\text { Düşünme }\end{array}$ \\
\hline 1 & $\begin{array}{l}\text { Teknoloji ile uzay araştırmaları arasındaki ilişkiyi } \\
\text { tahmin eder }\end{array}$ & & & $X$ \\
\hline 2 & $\begin{array}{l}\text { Güneş sistemindeki gezegenlerin dönme hızlarını, } \\
\text { Günş'e yakınlıkları ile ilişkilendirir. }\end{array}$ & $\mathrm{X}$ & & \\
\hline 3 & Teleskopların genel özelliklerini açıklar & & & $\mathrm{X}$ \\
\hline 4 & $\begin{array}{l}\text { Ünlü gökbilimcilerin çalışmaları hakkında çıkarımlarda } \\
\text { bulunur. }\end{array}$ & & & $\mathrm{X}$ \\
\hline 5 & $\begin{array}{l}\text { Uzay teleskoplarının gök biliminin gelişimindeki } \\
\text { önemini bilir. }\end{array}$ & $X$ & & \\
\hline 6 & $\begin{array}{l}\text { Gökyüzündeki takımyıldızlarının özelliklerini şekillerine } \\
\text { bakarak göre ayırt eder. }\end{array}$ & & $x$ & \\
\hline 7 & $\begin{array}{l}\text { Takımyıldızlarının Dünya'dan bakıldığındaki } \\
\text { görüntülerine bakarak yorumlar yapar. }\end{array}$ & & & $X$ \\
\hline 8 & $\begin{array}{l}\text { Kuyruklu yıldızların kirli kartopu olarak } \\
\text { adlandırıldığını bilir. }\end{array}$ & $\mathrm{X}$ & & \\
\hline 9 & $\begin{array}{l}\text { Evrenin oluşumuyla ilgili olarak öne sürülen Büyük } \\
\text { Patlama Teorisini bilir. }\end{array}$ & $X$ & & \\
\hline 10 & Gözlemevinin özelliklerini bilir. & $x$ & & \\
\hline 11 & Yıldızların özelliklerini bilir. & $X$ & & \\
\hline 12 & Gezegenlerin ısı ve ışık kaynağı olmadığını seçer. & & & $\mathrm{X}$ \\
\hline 13 & $\begin{array}{l}\text { Güneş sistemindeki gezegenleri Güneş'e yakınlıklarına } \\
\text { göre sıralar. }\end{array}$ & & $X$ & \\
\hline 14 & $\begin{array}{l}\text { Günlük yaşamda gökyüzü ile ilgili kullanılan yıldız } \\
\text { kayması ifadesini açıklar. }\end{array}$ & $X$ & & \\
\hline 15 & $\begin{array}{l}\text { Güneş sistemindeki gezegenleri özelliklerine göre } \\
\text { birbirleri ile karşılaştırır. }\end{array}$ & & $X$ & \\
\hline 16 & Güneş sistemindeki gezegenlerin özelliklerini bilir. & $\mathrm{X}$ & & \\
\hline 17 & Evren ve uzay kavramlarını birbirlerinden ayırt eder. & & & $X$ \\
\hline
\end{tabular}




\begin{tabular}{llll}
\hline 18 & Güneş sisteminin özelliklerini bilir. & $X$ & \\
\hline 19 & Gökbilimci ve astronot arasındaki farkı kavrar. & $X$ & \\
\hline 20 & Astrolojinin bir bilim dalı olmadı̆̆ını bilir. & $X$ & $X$ \\
\hline 21 & Göktaşı ve meteor kavramlarını birbirinden ayırt eder. & \\
\hline 22 & Kuyruklu yıldızların özelliklerini bilir. & $X$ & \\
\hline 23 & Yıldızların renkleri ile sıcaklıklarını ilişkilendirir. & & \\
\hline 24 & Yıldızların ve gezegenlerin özellikleri karşılaştırır. & $X$ & \\
\hline 25 & Uzay araçlarının özelliklerini bilir. & $X$ & $X$ \\
\hline 26 & Işık yılının özelliklerini bilir. & $X$ & \\
\hline 27 & Uzay kirliliğinin yol açacağı olası sonuçları tahmin eder. & \\
\hline
\end{tabular}

Yukarıda verilen Tablo 2'ye göre hazırlanan 27 soru alanında uzman iki fen eğitimcisi, bir fen bilgisi ve Türkçe öğretmeni tarafından incelenerek oluşturulmuştur. Uzman görüşlerine göre soru maddeleri kısadan uzuna doğru sıralanmış, olumsuz ifadelerden olabildiğince kaçınılmış, çeldiricilerin doğru bir şekilde hazırlanmasına dikkat edilmiştir. Ayrıca soruların kazanımlara uygunluğu da uzmanlar tarafından incelenmiştir.

\section{Astronomi başarı testi madde analizi}

Astronomi başarı testinden elde edilen sonuçların puanlanmasında; doğru cevaplar 1 puan, yanlış cevaplar, boş bırakanlar veya aynı madde için birden fazla cevabı işaretlemiş olanlar 0 puan olarak değerlendirilerek her öğrencinin testten aldığ toplam puan hesaplanmıştır. Her bir madde için öğrencilerin verdikleri cevaplar üzerinden madde analizi gerçekleştirilmiştir. Puanlama yapıldıktan sonra, elde edilen test puanları en yüksekten en düşüğe doğru sıralanmıştır. Puan sıralamasının, baştan ilk \%27'si üst grubu, sondan \%27'si alt grubu meydana getirecek şekilde gruplar oluşturularak madde analizi gerçekleştirilmiştir.

Taslak ABT için üst ve alt gruptaki öğrencilerin doğru sayısına göre madde analizi sonuçları Tablo 3'te verilmiştir.

Tablo 3. ABT'nin Pilot Madde Analizi Sonuçları

\begin{tabular}{lclll}
\hline Sorular & $\mathrm{P}_{\mathrm{j}}$ & Güçlük & $\mathrm{r}_{\mathrm{j}}$ & Ayırt edicilik \\
\hline 1.soru & .59 & Orta & .40 & Çok iyi \\
\hline 2. soru & .85 & Çok kolay & $.14^{*}$ & Çok zayıf \\
\hline 3. soru & .84 & Çok kolay & $.25^{*}$ & Düzeltilmeli \\
\hline
\end{tabular}




\begin{tabular}{|c|c|c|c|c|}
\hline 4. soru & .93 & Çok kolay & $.00^{*}$ & Çok zayıf \\
\hline 5. soru & .66 & Kolay & .49 & Çok iyi \\
\hline 6. soru & .60 & Orta & .41 & Çok iyi \\
\hline 7. soru & .55 & Orta & .50 & Çok iyi \\
\hline 8.madde & .48 & Orta & .67 & Çok iyi \\
\hline 9.madde & .60 & Orta & .44 & Çok iyi \\
\hline 10.madde & .66 & Kolay & .36 & $\overline{\text { İyi }}$ \\
\hline 11.madde & .55 & Orta & .51 & Çok iyi \\
\hline 12.madde & .54 & Orta & .48 & Çok iyi \\
\hline 13.madde & .74 & Kolay & $.27^{*}$ & Düzeltilmeli \\
\hline 14.madde & .61 & Orta & $.25^{*}$ & Düzeltilmeli \\
\hline 15.madde & .75 & Kolay & $.26^{*}$ & Düzeltilmeli \\
\hline 16.madde & .63 & Orta & .36 & İyi \\
\hline 17.madde & .62 & Orta & .39 & İyi \\
\hline 18.madde & .58 & Orta & $.25^{*}$ & Düzeltilmeli \\
\hline 19.madde & .67 & Kolay & .35 & İyi \\
\hline 20.madde & .55 & Orta & $.24^{*}$ & Düzeltilmeli \\
\hline 21.madde & .73 & Kolay & $.25^{*}$ & Düzeltilmeli \\
\hline 22.madde & .63 & Orta & .32 & İyi \\
\hline 23.madde & .71 & Kolay & $.17^{*}$ & Çok zayıf \\
\hline 24.madde & .86 & Çok kolay & $.06^{*}$ & Çok zayıf \\
\hline 25.madde & .44 & Orta & .36 & İyi \\
\hline 26.madde & .71 & Kolay & .31 & İyi \\
\hline 27.madde. & .47 & Orta & .36 & İyi \\
\hline 28.madde & .63 & Orta & .35 & İyi \\
\hline 29.madde & .57 & Orta & .51 & Çok İyi \\
\hline 30.madde & .51 & Orta & .54 & Çok iyi \\
\hline 31.madde & .53 & Orta & .50 & Çok iyi \\
\hline
\end{tabular}


Alan yazında $r \geq 0,25$ olan değerler için bu maddelerin bilen ile bilmeyen öğrencileri ayırt etmede başarılı maddeler olduğu belirtilmektedir (Çepni, Bayrakçeken, Yılmaz, Yücel, Semerci, Köse, Sezgin, Demircioğlu ve Gündoğdu, 2008). Tablo 'deki " $r$ " ( $r \geq 0$,25) değerleri incelendiğinde, 2, 4, 23, 24.soruların konu ile ilgili hedef ve davranışları karşılamaması ve " $r$ " değerlerinin 0,25'ten küçük olmasından dolayı başarı testinden çıkarılmasına karar verilmiştir. 31 maddelik test 27 sorudan oluşan başarı testinin ortalama madde güçlük indeksi $(P)$ 0,575 ve ortalama ayırt edicilik indeksi (D) ise 0,465 olarak bulunmuştur.

\section{Astronomi başarı testi güvenirlik analizi}

Bir testten öğrencilerin aldığı puanların güvenirliğine hizmet edebilecek bir başka istatistik tekniği ise Cronbach Alfa yöntemidir. Bu yöntem KR20 ile aynı mantık üzerine kurulu olduğundan, doğru yanıta bir, yanlış yanıta sıfır puan verilen testlerde kullanılabilir (Atılgan, 2013). Kullanılan bu istatistik teknikleriyle elde edilen katsayıya bakılarak testten öğrencilerin aldığı puanların güvenirliği hakkında yorum yapılabilir. Güvenirlik katsayısı sıfır ile bir arasında değişen bir sayı ile ifade edilir. Bu değerin bire yaklaşması oranında testten öğrencilerin aldığı puanların güvenirliği $\operatorname{artar}(G o ̈ m l e k s i z ~ \& ~ E r k a n, 2010)$. Cronbach Alfa katsayısının $(\alpha) 0.40$ dan düşüu olması testten öğrencilerin aldığı puanların güvenilir olmadığını, 0.40-0.60 arasında olması testten öğrencilerin aldığı puanların güvenirliğinin düşük olduğunu, 0.60-0.90 arasında olması testten öğrencilerin aldığı puanların oldukça güvenilir olduğunu, 0.90 nın üstünde olması ise testten öğrencilerin aldığı puanların yüksek derecede güvenilir olduğunu gösterir (Can, 2014). Bu çalışmada testten öğrencilerin aldığı puanların güvenirliğini belirlemek için Cronbach Alfa katsayısı kullanılmıştır. Bu test için güvenirlik katsayısı pilot çalışmada istenilen düzeltmeler yapıldıktan $\alpha=0.752$ olarak hesaplanmıştır. Bu değere bakılarak testten öğrencilerin aldığı puanların oldukça güvenilir olduğu söylenebilir.

Tablo 4. ATÖ Güvenirlik Analizi Sonuçları

\begin{tabular}{llllll}
\hline Aşama & Madde Sayısı & $\mathrm{N}$ & $\begin{array}{l}\text { Ort. Güçlük } \\
(\mathrm{pj})\end{array}$ & $\begin{array}{l}\text { Ort. Ayırt edicilik } \\
(\mathrm{rj})\end{array}$ & $\begin{array}{l}\text { Cronbach's } \\
\text { Alpha }\end{array}$ \\
\hline Pilot Test & 31 & 150 & .63 & .34 & .632 \\
\hline Nihai Test & 27 & 310 & .60 & .38 & .752 \\
\hline
\end{tabular}

\section{Tartışma ve Sonuç}

Bu araştırmada. 2017-2018 eğitim öğretim yılında 7. sınıf öğretim programında yer alan "Güneş sitemi ve Ötesi: Uzay Bilmecesi” ünitesi ile ilgili çoktan seçmeli sorulardan oluşan bir başarı testi hazırlanarak geçerlik ve güvenirlik çalışması yapılmıştır. Astronomi konuları ile ilgili yapılan nitel çalışmalar incelendiğinde; mevsimsel değişikliklerin nedenleri, Güneş, Dünya ve Ay'ın hareketleri, Güneş ve Ay 
tutulması, astronomik mesafeler ve yıldızlar gibi konular ile ilgili öğrencilerin düşünceleri, kavram yanılgıları ve kavramsal değişimleri açık uçlu sorular ve görüşme yöntemleriyle belirlenmeye çalışılmıştır (Alın ve İzgi, 2017; Bakas ve Mikropoulos, 2003; Fanetti, 2001; Miller ve Brewer, 2010; Sarrazine, 2005; Starakis ve Halkia, 2010; Trumper, 2006; Zeilik ve ark. 1998).

Ayrıca Dünya ve Evren konu alanıyla ilgili alan yazın incelendiğinde, çalışmaların büyük bölümünün Dünya, Güneş, Ay, Evren ve Mevsimler konularına ilişkin meteor ve göktaşı, yıldızlar, yıldız kayması, kuyruklu yıldız, güneş, gezegen, gel git olayı, uzay, gökada, evren, astronomi birimi (AB), ışık yılı, uzay kirliliği kavramları ile ilgili öğrencilerin kavram yanılgılarını ve zihinsel modellerini belirlemeye yönelik olduğu tespit edilmiştir. İncelenen bu çalışmalarda farklı öğrenci seviyelerine yönelik, birbirinden farklı astronomi kavramlarını içeren başarı testleri geliştirildiği görülmüştür (Baloğlu Uğurlu, 2005; Bailey, Prather \& Slater, 2012; Bektaşl1, 2013; Bektaşl1, 2016; Bostan, 2008; Ekiz, \& Akbaş, 2005; Kurnaz \& Değirmenci, 2012; Slater, Schleigh, \& Stork, 2015; Trumper, 2001; Türk, Alemdar \& Kalkan, 2012; Wallace, 2011). Bu çalışmalarda çoktan seçmeli testler ile çeşitli öğrenim kademelerindeki öğrencilerin bilgi düzeyleri, zihinsel modelleri, kavram yanılgıları ortaya konmuştur. Bu çalışmalar arasından sadece “Güneş Sistemi ve Ötesi: Uzay Bilmecesi" ünitesi kazanımlarına yönelik geliştirilen başarı testlerinin de sınırlı sayıda olduğu tespit edilmiştir (Arıkurt, 2014; Buluş-Kırıkkaya ve Şentürk, 2018; Çepni ve Şenel Çoruhlu, 2014; Demirçalı, 2016; Deniş Çeliker, 2012; Gülen ve Demirkuş, 2014; Gündoğdu, 2014; Türk, 2015).

Bu nedenle bu çalışmada 7.sınıf "Güneş Sistemi ve Ötesi: Uzay Bilmecesi” ünitesi kazanımlarına yönelik başarı testi geliştirilmiştir. Güvenirlik sonuçlarına baktığımızda, nihai astronomi başarı testinin Cronbach alfa güvenirlik katsayısı .752 olarak hesaplanmıştır. Özdamar (2004) alfa güvenirlik katsayısının değerlendirilmesinde $0.60 \leq \alpha<0.80$ arasını "oldukça güvenilir" olarak tanımlamıştır. Bu sonuçla ABT'nin güvenilir bir test olduğu söylenebilir.

\section{Öneriler}

- Bu test 7. sınıf Güneş Sistemi ve Ötesi: Uzay Bilmecesi ünitesi için hazırlanmıştır. Öğretim programında yer alan 6. ve 8. sınıf astronomi ünitelerinin kazanımlarını kapsayan testler de oluşturulabilir.

- Öğretim programında yer alan kazanımları kapsayan bu test, ünite başında ve sonunda öğrencilerin eksiklerini belirlemek için kullanılabilir.

- Bu çalışmada yer alan sorular Haladyna Taksonomisi'nin anlama, problem çözme ve eleştirel düşünme süreçlerine göre hazırlanmıştır. Bu konuda çalışma yapmak isteyen araştırmacılar, Haladyna Taksonomisi'nin yaratıcılık düşünme sürecine göre de soru hazırlayabilirler. 


\section{Kaynaklar}

Açıkgöz, M. \& Karslı, F. (2015). Alternatif ölçme-değerlendirme yaklaşımları kullanılarak iş ve enerji konusunda geliştirilen başarı testinin geçerlilik ve güvenirlik analizi. Amasya Üniversitesi Ĕ̆itim Fakültesi Dergisi, 4(1), 1-25.

Agan, L. (2004). Stellar ideas: Exploring students' understanding of stars. Astronomy Education Review,3(1).

Kurnaz M. A., Bozdemir H.,Deniz Altunoğlu B., Ezberci Çevik E.(2016). Fen eğitiminde astronomi konu alanında yayınlanan ulusal makalelerin incelenmesi. Erzincan Üniversitesi Ĕ̆gitim Fakültesi Dergisi. 18 (2 ).1398-1417.

Alın, G. ve İzgi, Ü. (2017). İlköğretim öğrencilerinin yıldızlar konusuna ilişkin kavram yanılgilarının incelenmesi, Sosyal Bilimler Dergisi,10(4), 202-214.

Arıcı, V. A. (2013). Fen Ĕ̆itiminde Sanal Gerçeklik Programları Üzerine Bir Çalışma:" Güneş Sistemi ve Ötesi: Uzay Bilmecesi" Ünitesi Örneği. (Yayınlanmamış Yüksek lisans Tezi).Adnan Menderes Üniversitesi, Sosyal Bilimler Enstitüsü

Arıkurt, E., Durukan, Ü. G. ve Şahin, Ç. (2015). Farklı öğrenim seviyesindeki öğrencilerin astronomi kavramıla ilgili görüşlerinin gelişimsel olarak incelenmesi. Amasya Üniversitesi Ĕ̆gitim Fakültesi Dergisi, 4 (1), 66-91.

Atılgan, H. (Ed.) (2013). Eğitimde ölçme ve değerlendirme (6. Baskı). Ankara: Anı Yayıncılık.

Bailey, J. M. (2006). Development of a concept inventory to assess students' understanding and reasoning difficulties about the properties and formation of stars, Doctorate Thesis, Arizona University, ABD

Bailey, J. M., Johnson, B., Prather, E. E., \& Slater, T. F. (2012). Development and validation of the star properties concept inventory. International Journal of Science Education, 34(14), 2257-2286.

Bakas, C. \& Mikropoulos, T. (2003). Design of virtual environments for the comprehension of planetary phenomena based on students' ideas, International Journal of Science Education, 25(8), 949-967

Balbağ, M.Z. ve Erdem, A. (2017). Fen bilgisi öğretmenliği ve fizik bölümü öğrencilerinin astronomiye yönelik tutumlarının bazı değişkenler açısından incelenmesi, Kastamonu Eğitim Dergisi, 25(5), 2007-2018.

Balcı,M.(2018). Webquest destekli etkinliklerin öğrencilerin güneş sistemi ünitesindeki başarısına ve astronomiye yönelik tutumuna etkisi. Yüksek Lisans Tezi. Hacettepe Üniversitesi, Eğitim Bilimleri Enstitüsü, Ankara. 
Baloğlu-Uğurlu, N. (2005). İlköğretim 6. sinıf öğrencilerinin dünya ve evren konusu ile ilgili kavram yanılgıları, Gazi Eğitim Fakültesi Dergisi, 25(1), 229-246.

Baltacı, A. (2013). Astronomi konusunun çoklu yazma etkinlikleri ve yaparak yazarak bilim öğrenme metodu kullanılarak öğretimimin değerlendirilmesi. (Yayınlanmamış Yüksek Lisans Tezi). Marmara Üniversitesi, Eğitim Bilimleri Enstitüsü, İstanbul.

Başakcı G. (2018). Gezici planetaryumların ortaokul 7. sınıf öğrencilerinin bazı astronomi konuların öğrenimine ve astronomiye yönelik tutumlarına etkisinin incelenmesi. Yükseklisans tezi. Çukurova Üniversitesi Sosyal Bilimler Enstitüsü, Adana. Bekiroğlu, F.O. (2007). Effects of model-based teaching on preservice physics teachers' conceptions of the moon, moon phases and other lunar phenomena, International Journal of Science Education, 29(5), 55.

Bektaşlı, B. (2013). The effect of media on preservice science teachers' attitudes toward astronomy and achievement in astronomy class. TOJET: The Turkish Online Journal of Educational Technology, 12(1), 139-146.

Bektaşlı, B. (2016). The relationship between preservice science teachers' attitude toward astronomy and their understanding of basic astronomy concepts. International Journal of Progressive Education, 12(1), 108-116.

Bostan A., 2008. Farklı yaş grubu öğrencilerinin astronominin bazı temel kavramlarına ilişkin düşünceleri (Yayınlanmamış yüksek lisans tezi). Balıkesir Üniversitesi,Fen Bilimleri Enstitüsü, Balıkesir.

Buluş Kırıkkaya, E. ve Şentürk, M. (2018). Güneş sistemi ve ötesi ünitesinde artırılmış gerçeklik teknolojisi kullanılmasının öğrenci akademik başarısına etkisi, Kastamonu Üniversitesi Kastamonu Ĕ̆itim Dergisi, 26(1), 181-189.

Bülbül, E., İyibil, Ü. G. ve Şahin, Ç. (2013). Ortaokul 8.sınıf öğrencilerinin astronomi kavramıyla ilgili algılamalarının belirlenmesi, Ĕ̆itim ve Öğretim Araştırmaları Dergisi, $2(3), 170-179$.

Büyüköztürk, Ş., Çakmak, E.K., Akgün, Ö.E., Karadeniz, Ş. ve Demirel, F. (2010). Bilimsel araştırma yöntemleri. Ankara: Pegem Yayıncılık.

Can, A. (2014). SPSS ile bilimsel araştırma sürecinde nicel veri analizi, Pegem A Yayıncılık, Ankara.

Clements, D. H. (1999). Geometric and spatial thinking in young children. In J. V. Copley (Ed.), Mathematics in the early years (pp. 66-79). Reston, VA: National Council of Teachers of Mathematics. 
Colombo, P., D., Jr. Silva, C., C., ve Aroca, S., C. (2010). Daytime school guided visits to an astronomical observatory In Brazil. Astronomy Education Review, 9(1), 010113

Çepni, S., \& Şenel Çoruhlu, T.. (2014). “Güneş Sistemi ve Ötesi: Uzay Bilmecesi” ünitesinde zenginleştirilmiş 5E öğretim modeline uygun hazırlanan öğrenme ortamlarının öğrenci başarısı üzerine etkisinin incelenmesi. Uludă̆ Üniversitesi Ĕ̆gitim Fakültesi Dergisi, 27(2), 343-369.

Çepni, S., Bayrakçeken, S., Yılmaz, A., Yücel, C., Semerci, Ç., Köse, E., Sezgin, F., Demircioğlu, G. ve Gündoğdu, K. (2008). Ölçme ve Değerlendirme. Ankara: Pagem Akademi

Demir, N., Kızılay, E., \& Bektaş, O. (2016). 7. Sınıf çözeltiler konusunda başarı testi geliştirme: geçerlik ve güvenirlik çalışması. Necatibey Eğitim Fakültesi Elektronik Fen ve Matematik Eğitimi Dergisi,10(1).209-237.

Demir N., Öner Armağan F.(2018a). Ortaokul öğrencilerinin planetaryumlara yönelik görüşleri, The Journal of International Education Science, 18(5),118-131.

Demir N., Öner Armağan F.(2018). Okul dışı öğrenme ortamlarına yönelik fen bilgisi öğretmenlerinin görüşleri: Planetaryum, Journal of Social Humanıtıes Sciences Research,30(5), 4241-4248.

Demir N., Öner Armağan F.(2019). Astronomiye yönelik tutum ölçeği geliştirilmesi: Geçerlik ve güvenirlik çalışması. Social Science Studies Journal, 35(5),2718-2731.

Demirçalı, S. (2016). Modellemeye dayalı fen öğretiminin öğrencilerin akademik başarılarına, bilimsel süreç becerilerine ve zihinsel model gelişimlerine etkisi: 7.sınf güneş sistemi ve ötesi-uzay bilmecesi ünitesi örneğgi. (Yayımlanmamış Doktora Tezi). Gazi Üniversitesi Eğitim Bilimleri Enstitüsü, Ankara.

Deniş Çeliker, H. (2012).Fen ve teknoloji dersi "güneş sistemi ve ötesi: uzay bilmecesi" ünitesinde proje tabanlı öğrenme uygulamalarının öğrenci başarılarına, yaratıcı düşünmelerine, fen ve teknolojiye yönelik tutumlarına etkisi. (Doktora Tezi). Dokuz Eylül Üniversitesi Eğitim Bilimleri Enstitüsü, İzmir.

Ekiz, D., \& Akbaş, Y. (2005). İlköğretim 6. sınıf öğrencilerinin astronomi ile ilgili kavramları anlama düzeyi ve kavram yanılgıları.Milli Ĕ̆itim Dergisi,165, 61-78.

Fanetti, T. M. (2001). The relationships of scale concepts on college age students' misconceptions about the cause of lunar phases (Unpublished master's thesis). Iowa State University.

Fraenkel, J. R., Wallen, N. E., \& Hyun, H. (2012). How to design and evaluate research in education (8th ed.). New York: McGraw Hill.cl

Gömleksiz, M. ve Erkan, S. (2010). Eğitimde ölçme ve değerlendirme, Nobel Yayın Dağıtım. 
Ankara.

Gülen, S., \& Demirkuş, N. (2014). “Güneş Sistemi ve Ötesi: Uzay Bilmecesi” ünitesinde, görsel materyalin öğrenci başarısına etkisi. Yüzüncü Yıl Üniversitesi Eğitim Fakültesi Dergisi, 11(1), 1-19.

Gündoğdu, T. (2014). 8. sını öğrencilerinin astronomi konusundaki başarı ve kavramsal anlama düzeyleri ile fen dersine yönelik tutumları arasındaki ilişkinin incelenmesi.(Yayınlanmamış yüksek lisans tezi). Marmara Üniversitesi Eğitim Bilimleri Enstitüsü, İstanbul.

İpek Akbulut, H. \& Çepni, S. (2013). Bir üniteye yönelik başarı testi nasıl geliştirilir? :İlköğretim 7. sınıf kuvvet ve hareket ünitesine yönelik bir çalışma. Amasya Üniversitesi Ĕ̆gitim Fakültesi Dergisi, 2(1), 18-44.

İyibil, Ü.G. (2010). Farkl programlarda öğrenim gören öğretmen adaylarının temel astronomi kavramların anlama düzeylerinin ve ilgili kavramlara ait zihinsel modellerinin analizi, Yayımlanmamış Yüksek Lisans Tezi, Fen Bilimleri Enstitüsü, Karadeniz Teknik Üniversitesi, Trabzon.

İyibil, Ü.G. \& Sağlam Arslan, A. (2010). Fizik öğretmen adaylarının yıldız kavramına dair zihinsel modelleri, Necatibey Eğitim Fakültesi Elektronik Fen ve Matematik Eğitimi Dergisi, 4(2), 25-46

Kallery, M. (2001). Early-years educators' attitudes to science and pseudo- science: the case of astronomy and astrology. European Journal of Teacher Education , 24(3), 329-342.

Karaatlı, M. (2006). Verilerin düzenlenmesi ve gösterimi. SPSS uygulamal çok değişkenli istatistik teknikleri. (Ed. Şeref Kalayc1), İkinci Baskı, Ankara: Asil Yayınları.

Karip, E. (2012). Ölçme ve değerlendirme. Ankara: Pegem A Yayıncılık

Kenan, O. \& Özmen, H. (2014). Maddenin tanecikli yapısına yönelik iki aşamalı çoktan seçmeli bir testin geliştirilmesi ve uygulanması. Journal of Research in Education and Teaching, 3(3), 371-378.

Kızkapan,O. \&Bektaş O.(2018). Fen eğitiminde başarı testi geliştirilmesi: hücre bölünmesi ve kalıtım örneği. Uluslararası Eğitim Bilimleri Dergisi. 2(1):1-18.

Kikas, E. (2005). Development of children's knowledge: the sky, the Earth and the Sun in children's explanations, Electronic Journal of Folklore, 31, 31- 56.

Kurnaz, M. A. ve Değirmenci, A. (2011). Temel astronomi kavramlarına ilişkin öğrenci algılamalarının sınıf seviyelerine göre karşılaştırması. Mehmet Akif Ersoy Üniversitesi Eğitim Fakültesi Dergisi, 22, 91-112.

Kurnaz, M. A., \& Değermenci, A. (2012). 7. sınıf öğrencilerinin Güneş, Dünya ve Ay ile ilgili 
zihinsel modelleri. Illköğretim Online,11(1).137-150.

Kurnaz, M. A. (2012). Yıldız, kuyruklu yıldız ve takımyıldız kavramlarıyla ilgili öğrenci algılamalarının belirlenmesi, Abant İzet Baysal University Education Faculty Journal, 12(1), 251264.

Milli Egitim Bakanligi (MEB). (2018). Curriculum of science course teaching. Retrieved from http://mufredat.meb.gov.tr/ProgramDetay.aspx?PID=325

Miller, B. W. \& Brewer, W. F. (2010). Misconceptions of astronomical distances, International Journal of Science Education, 32(12), 1549-1560.

Öcal, E. (2014). Vücudumuzdaki sistemler ünitesinin öğretiminde drama yönteminin ve kukla/ karagöz uygulamalarının öğrenci başarısı ve tutuma etkisi. Doktora Tezi, Gazi Üniversitesi, Eğitim Bilimleri Enstitüsü, Ankara.

Öner, Öz., Ö.(2004).Illköğretim 6. smıflarda fen bilgisi dersinde uzayı keşfediyoruz ünitesinin öğretiminde bilgisayar destekli öğretimin öğrenci başarısına etkisi (Yayınlanmamış Yüksek Lisans Tezi). Çukurova Üniversitesi, Sosyal Bilimler Enstitüsü, Adana.

Özdamar, K. (2004). Paket programlar ile istatistiksel veri analizi 1. (5. Baskı). Eskişehir: Kaan Kitabevi.

Slater, S. J., Schleigh, S. P., \& Stork, D. J. (2015). Analysis of individual Test Of Astronomy STandards (TOAST) item responses. Journal of Astronomy \& Earth Sciences Education, 2(2).

Saraç, H. (2018). Fen Bilimleri dersi 'maddenin değişimi' ünitesi ile ilgili başarı testi geliştirme: Geçerlik ve güvenirlik çalışması. Abant İzzet Baysal Üniversitesi Ĕ̆itim Fakültesi Dergisi, $18(1), 416-445$.

Sarrazine, A. R. (2005). Addressing astronomy misconceptions and achieving national science standards utilizing aspects of multiple intelligences theory in the classroom and the planetarium (Unpublished doctoral dissertation). Department of Curriculum \& Instruction, Indiana University.

Saylan Kırmızıgül, A., ., \&Kaya H.. (2019). ‘aynalarda yansıma ve ışı̆̆ın soğrulması'konusunda geçerliliği ve güvenilirliği sağlanmış başarı testi geliştirme çalışması. Journal of Theoretical Educational Science, 12(2), 474-493.

Starakis, J. \& Halkia, K. (2010). Primary school students"e ideas concerning the apparent movement of the moon, Astronomy Education Review, 9(1),DOI:10.3847/AER2010007.

Şahin, F. (2001). İlköğretim 2. sınıf öğrencilerinin uzay hakkındaki bilgilerinin 
değerlendirilmesi, Burdur Ĕ̆itim Fakültesi Dergisi, 2, 156-169.

Şenel Çoruhlu, T. (2013). Güneş sistemi ve ötesi uzay bilmecesi ünitesinde zenginleştirilmiş 5e öğretim modeline göre geliştirilen rehber materyallerin etkililiğinin belirlenmesi. Yayımlanmamış doktora tezi, Eğitim Bilimleri Enstitüsü, Karadeniz Teknik Üniversitesi, Trabzon.

Şener, N. \& Taş, E. (2017). Developing achievement test: A research for assessment of 5th grade biology subject. Journal of Education and Learning, 6(2), 254.

Trumper, R. (2001). Assessing students' basic astronomy conceptions from junior high school through university. Australian Science Teachers Journal, 41, 21-31.

Trumper, R. (2006). Teaching future teachers basic astronomy concepts-seasonal changes-at a time of reform in science education. Journal of Research of Science Teaching, 43 (9), 879-906.

Turgut, M.F. (1992). Eğitimde Ölçme ve Değerlendirme. Ankara: Saydam Matbaacılık. Türk,C. (2015). Modellerle astronomi öğretiminin etkililiği. Doktora Tezi. Ondokuz Mayıs Üniversitesi,Eğitim Bilimleri Enstitüsü, Samsun.

Türk, C., Alemdar, M., \& Kalkan, H. (2012). İlköğretim öğrencilerinin mevsimler konusunu kavrama düzeylerinin saptanması. Dünya'daki Eğitim ve Öğretim Çalışmaları Dergisi, 2(1), 62-67.

Türk, C. ve Kalkan, H. (2017a). Yükseköğretim öğrencilerine yönelik astronomi tutum ölçeği uyarlama çalışması, Sosyal Bilimler Dergisi, 15(3), Doi: 10.18026/cbayarsos.340970.

Türk, C. ve Kalkan, H. (2017b). Modellerle astronomi öğretiminin öğrencilerin başarılarına ve tutumlarma etkisi, Journal of Current Researches on Educational Studies (JoCuRES), 7(2), doi: 10.26579/jocures-7.2.12.

Wallace, C.S. (2011). An investigation into introductory astronomy students' difficulties with cosmology, and the development, validation, and efficacy of a new suite of cosmology lecture-tutorials. Ph.D. Dissertation, University of Colorado

Yılmaz, E. (2014).7. sinıf temel astronomi kavramlarına etkin öğretimine yönelik bir eylem araştırması (Yayınlanmamış Yüksek Lisans Tezi). DEÜ Eğitim Bilimleri Ensitüsü, İzmir.

Yurdabakan, İ. (2008). Eğitimde kullanılan ölçme araçlarının nitelikleri. Erkan, S. Ve Gömleksiz, M., (Ed.), Eğitimde ölçme ve değerlendirme. (38-66). Ankara: Nobel Yayın Dağıtım.

Zeilik, M., Schau, C., \& Mattern, N. (1998). Misconceptions and their change in university 
astronomy courses, The Physics Teacher, 36, 104-107.

Zeilik, M., Schau, C., \& Mattern, N. (1999). Conceptual astronomy. II. Replicating conceptual gains, probing attitude changes across three semesters. American Journal of Physics,67(10), 923-927. 